\title{
Minocycline-induced Hyperpigmentation
}

\author{
Timothy Judson, MD, MPH' and Kip Mihara, $\mathrm{MD}^{1,2}$
}

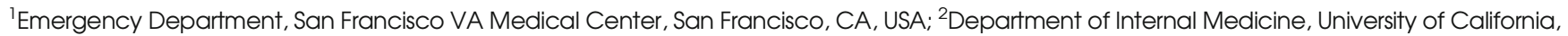
San Francisco, CA, USA.

KEY WORDS: clinical image; dermatology; pharmaceutical care. J Gen Intern Med 32(1):133

DOI: $10.1007 / \mathrm{s} 11606-016-3735-\mathrm{x}$

(c) Society of General Internal Medicine 2016

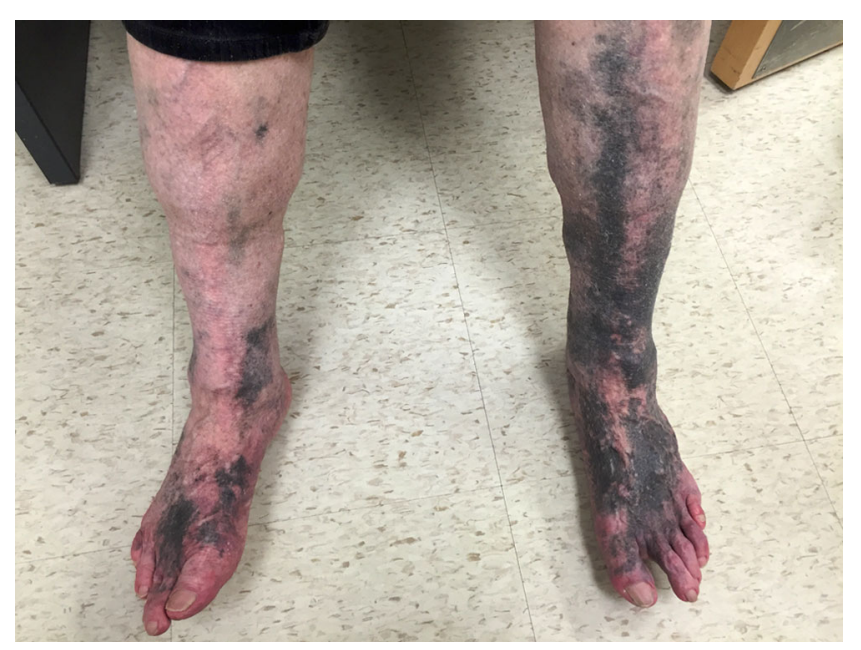

Figure 1 Hyperpigmented macules on the lower extremities.

A 76-year-old man presented with areas of progressive $A$ skin darkening for 2 years. On exam, he had hyperpigmented, non-blanching coalescent macules on his arms, legs, and abdomen (Figs. 1 and 2). They were painless and non-pruritic. He had been taking minocycline as suppressive therapy for an infection that complicated a C3-C7 laminectomy and posterior fusion 27 months earlier. He was diagnosed with minocycline-induced hyperpigmentation (MIH).

The differential diagnosis for acquired hyperpigmentation includes melasma, pigmented contact dermatitis, druginduced hyperpigmentation (DIH), erythema dyschromicum perstans, Addison's disease, hyperthyroidism, hemochromatosis, and cutaneous malignancies. These disorders generally result from increased melanin, increased melanocytes, or deposition of another discoloring substance in the skin. ${ }^{1}$ Medications commonly cited as causing hyperpigmentation include prostaglandins, minocycline, phenothiazine, nicotine, and antimalarial drugs. ${ }^{2}$ MIH typically occurs in a dose-dependent fashion after large cumulative doses of 70-100 g, but may

Received April 6, 2016

Accepted April 29, 2016

Published online May 12, 2016

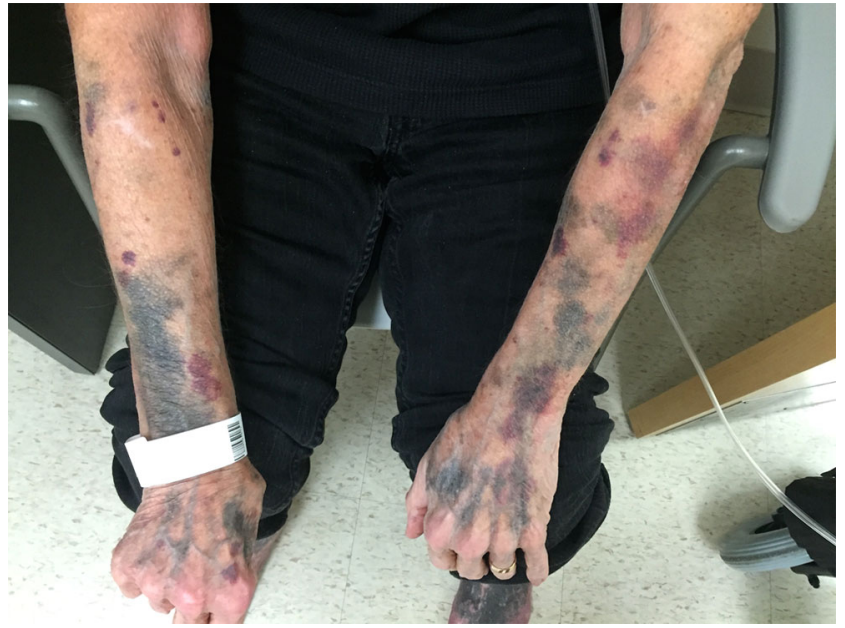

Figure 2 Hyperpigmented macules on the upper extremities.

appear within weeks of starting the medication. ${ }^{3}$ In one study, $17 \%$ of patients taking minocycline developed hyperpigmentation. ${ }^{4}$ In addition to the skin, MIH can involve the sclera, nails, ear cartilage, bone, oral mucosa, teeth, and thyroid gland. ${ }^{5}$ Therapy for $\mathrm{MIH}$ is cessation of the medication, after which the discoloration may slowly improve. If discoloration persists, laser therapy may also be used. ${ }^{5}$

Corresponding Author: Kip Mihara, MD; Emergency Department, San Francisco VA Medical Center, 4150 Clement Street, Mail code 111A3, San Francisco, CA 94121, USA (e-mail: Kip.mihara@va.gov).

\section{Compliance with Ethical Standards:}

Conflict of Interest: The authors declare that they do not have a conflict of interest.

Funding: None

\section{REFERENCES}

1. Stulberg DL, Clark N. Common hyperpigmentation disorders in adults: Part I. Diagnostic approach, Café au Lait macules, diffuse hyperpigmentation, sun exposure, and phototoxic reactions. Am Fam Physician. 2003;68(10): 1955-61.

2. Krause W. Drug-induced hyperpigmentation: a systematic review. J Dtsch Dermatol Ges. 2013;11(7):644-51.

3. Eisen D, Hakim MD. Minocycline-induced pigmentation. Incidence, prevention and management. Drug Saf. 1998;18(6):431-40.

4. O'dell JR, Paulsen G, Haire CE, et al. Treatment of early seropositive rheumatoid arthritis with minocycline: four-year followup of a double-blind, placebo-controlled trial. Arthritis Rheum. 1999;42(8):1691-5.

5. James WD, ELston DM, Berger TG. Andrews' diseases of the skin: clinical dermatology. 11th ed. London: Saunders/Elsevier; 2011:126. 